\title{
Gift exchange and the business cycle: the fair wage strikes back
}

\author{
Fabrice Collard*i David de la Croix ${ }^{\ddagger}$ \\ First draft: December 1996 \\ This version: April 1997
}

\begin{abstract}
We extend the benchmark RBC model amending the technology for efficiency wage considerations. The disutility of effort depends on current, alternative and past wages. Past wages are treated as the worker's past wages (personal norm case) or as the past wages of the society (social norm case). This last model reproduces the high variability of employment, the low variability of wages and the low wageemployment correlation without requiring a second source of impulsions. Moreover the dynamics of wages and employment is adequately captured when norms adjust slowly to the environment. Efficiency wages are thus useful to solve the business cycle puzzle when we allow for inter-temporal wage comparisons.
\end{abstract}

JEL Classification: E24

Keywords: efficiency wage, effort, time-non-separability, RBC, wage sluggishness, business cycle puzzle.

${ }^{*}$ We are grateful to H. Dellas, J. Duran, M. Eichenbaum, P.Y. Hénin, P. Malgrange and F. Portier for helpful comments on a previous version.

${ }^{\dagger}$ IRES, Université catholique de Louvain, Place Montesquieu 3, B-1348 Louvain-la-Neuve, Belgium and M.A.D., Université de Paris I. E-mail: collard@ires.ucl.ac.be.

$\ddagger$ National Fund for Scientific Research and IRES, Université catholique de Louvain, Place Montesquieu 3, B-1348 Louvain-la-Neuve, Belgium. E-mail: delacroix@ires.ucl.ac.be. The financial support of the PAC program 93/98-162 of the Ministry of Scientific Research (French Speaking Community, Belgium) is gratefully acknowledged. 


\section{Introduction}

One major challenge of macroeconomics is to propose rigorous and convincing explanations of why real wages may be rigid and why employment fluctuates largely in response to shocks. Indeed, the inspection of the U.S. business cycle characteristics of the labor market aggregates shows that the volatility of labor input is high and greater than the volatility of wages. Moreover, the correlation between wages and output is moderate (see Cooley and Prescott (1995)). The standard Real Business Cycle model, see e.g. King, Plosser and Rebelo (1988), failed to account for these facts. Solving this "business cycle puzzle" has become one of the most challenging task for the RBC research program. ${ }^{1}$

Assuming that productivity and workers' effort are affected by the wage paid by the firm, efficiency wage theories have been judged to be very promising given the goal of understanding labor market characteristics (see e.g. Blanchard and Fischer, 1989, p.463). These theories have first been developed in static models, explaining the existence of involuntary unemployment in terms of the optimal response of firms to workers' behavior. For instance, in the partial gift exchange model of Akerlof (1982), the effort of an individual worker depends on a comparison between the current wage and a norm which includes the salaries perceived by other workers, the level of unemployment and unemployment benefits, and the actual wage of the individual in previous periods. ${ }^{2}$ The optimal response of the firm to this behavior is to offer a wage above the market-clearing level in exchange of which workers would provide a higher level of effort. This view of the labor relation is supported by a large number of researches both in applied economics and experimental psychology. ${ }^{3}$

The hopes generated by the efficiency wage theories were strongly deceived by further studies in the framework of stochastic dynamic general equilibrium models. Danthine and Donaldson (1990) conclude that "The most striking implication to emerge from these data is the inability of our gift exchange example to account for the business cycle puzzle. This result is important because it demonstrates that in efficiency wage models involuntary unemployment (...) is not synonymous with wage sluggishness. (...) most of the adjustment to productivity shocks is in terms of wages. There is almost no adjustment in terms of quantities." A similar disappointment with regard to efficiency wage models can be found in Uhlig and $\mathrm{Xu}$ (1995). They find that, in order to reproduce an adequate level of employment variability, they need to assume implausibly large movements in the technological shock. The reason is that effort moves countercyclically, because the wage norm depends negatively on unemployment.

The conclusion that efficiency wage considerations based on the gift exchange paradigm

\footnotetext{
${ }^{1}$ See for instance the contributions of Christiano and Eichenbaum (1992) and Fève and Langot (1994).

${ }^{2}$ Notice that this last element has been omitted in the various subsequent analyses because the majority of them are performed in static frameworks.

${ }^{3} \mathrm{~A}$ representative study in this category which precedes the theoretical formulation of the efficiency wage models is the one of Adams and Rosenbaum (1962). The agents in this experiment were male college students who were hired on a part-time basis to conduct interviews at a given salary per hour. After completing an extensive questionnaire, agents in the control group were informed that they were suitably qualified for the job. In the experimental group, agents were told that their questionnaires revealed them to be under qualified, but that they would be hired and paid the preestablished rate nevertheless. This manipulation led agents in the experimental group to feel they were overpaid compared to the agents in the control group. The results revealed that the agents in the experimental group conducted more interviews per hour than those in the control group, thereby lending support to the theory.
} 
are not sufficient to resolve the business cycle puzzle (Danthine and Donaldson, 1995) seems too hasty because the mentioned studies have never used the original idea of Akerlof (1982) that the wage norm depends also on past wages. It is clear that this time-nonseparability in the disutility of effort could not have been analyzed in the initial static studies of efficiency wages, but it seems feasible and desirable to use it in the more sophisticated dynamic models of the RBC type. This position is reinforced by the fact that there is also a bunch of empirical studies which stresses the importance of intertemporal wage comparisons for effort and job satisfaction.

For instance, examining the benchmarks used in the evaluation of payments, Goodman (1974) found that an important proportion of respondents to his survey used their own payment in the past as a comparison standard. Another interesting study has been carried out by Lord and Hohenfeld (1979). They compared the performance of baseball players who were paid less one season than they were the season before. Using their own salaries during the previous year as a basis for comparison, they were expected to have felt underpaid. As the theory predicts, these players lowered their performance. A more recent micro-econometric study of Wadhwani and Wall (1991) uses a panel on U.K. manufacturing enterprises to estimate their production function (including thus the effort function). They allow the wage norm to depend on past wages and show that there is some evidence in favor of this dependence. Additional inference on the role of past wages on effort can be done by analyzing job satisfaction studies. Using a panel data on British employees, Clark (1996) provides evidence that job satisfaction is strongly positively correlated with the change in the worker's payment between the two waves of the panel.

Applying the terminology of Becker (1996) to our problem, the inclusion of past wages in the norm can be achieved in two distinct ways: (a) The personal norm includes the relevant past wages perceived by the individual; (b) The social norm incorporates the influence of past actions by peers and others. This distinction is crucial for the type of dynamics which will emerge from the model. In the personal norm case, the firm recognizes the impact of the current wage on the future effort levels of its workers. In the social norm case, the firm has no control on the "social capital" of its workers since it is mainly determined by the situations of peers and relevant others. In the majority of the mentioned empirical studies, the authors have implicitly in mind the social norm case. However, in a fully specified dynamic model with rational expectations, the alternative of the personal norm case could also be of interest. In that case, the problem of the firm should be analyzed as a truly dynamic problem. The two cases will be treated in turn.

The aim of this paper is thus to evaluate whether incorporating past wage comparisons in efficiency wage models can help to solve the business cycle puzzle related to the labor market and hence promote a new direction for research. The evaluation of the performance of the model is carried out using standard real business cycle techniques, including the comparisons of the properties of the data generated by a stylized calibrated model with the one of the data from the real world. The moments on which the comparison will bear are essentially the volatility and the correlation of hours and wages with respect to output. We also examine the ability of the model to mimic the dynamic pattern of wages and hours. An important characteristic of this research is that it provides a very simple extension of Danthine and Donaldson (1990) to allow effort to depend on past wages. The model has no additional features such as labor adjustment-costs, labor hoarding or 
time-to-build.

The structure of the paper is as follows. The two versions (personal norm and social norm) of the model are described in a first section. The second section presents the stylized facts of the labor market that we would like to reproduce and analyzes the performance of the two models in terms of moment matching. Section 3 analyses the implications of the model in terms of wage and employment dynamics. An extension of the model in which norms adjust slowly is proposed and evaluated. Section 4 concludes.

\section{The model}

We develop in this paper a model in the lines proposed by Danthine and Donaldson (1990). This paper broadens the benchmark RBC model amending the technology for efficiency wages considerations. In their gift exchange model, effort is an increasing function of current wage $\left(w_{t}\right)$, and decreases with the current alternative wage $\left(w_{t}^{a}\right)$ which serves as a benchmark for the workers to evaluate their salary. We amend this effort function for past wage consideration. Efficiency of labor will be a function of current, wage and past wage : $e_{t}=e\left(w_{t}, w_{t}^{a}, w_{t-1}\right)$. We treat the past wage in two ways. First, it is viewed as the past wage of the society, bearing upon the social capital of workers. We call this case the social norm case. Second, it is the own past wage of the worker, and we call it a personal norm. We first present the behavior of an household concerning its consumption-saving decision before considering the behavior of firms.

\subsection{The household}

The economy is populated by many identical infinitely lived agents, uniformly distributed on $[0,1]$. Each household has to define a consumption-savings plan such that he maximizes his discounted expected utility, subject to his intertemporal budget constraint:

$$
\begin{array}{ll} 
& \max E_{0} \sum_{t=0}^{\infty} \beta^{t}\left[\log c_{t}-d_{t}\left(e_{t}-\phi-\gamma \log \left(\frac{w_{t}}{w_{t}^{a}}\right)-\psi \log \left(\frac{w_{t}}{w_{t-1}}\right)\right)^{2}\right] \\
\text { s.t. } & c_{t}+\int_{A} \frac{p_{t+1}\left(a_{t+1} \mid a^{t}\right)}{p_{t}\left(a_{t} \mid a^{t-1}\right)} b_{t+1}\left(a_{t+1} \mid a^{t}\right) \mathrm{d} a_{t+1} \leq b_{t}+w_{t}\left(1-u_{t}\right)
\end{array}
$$

in which $E_{t}\left(X_{t+1}\right)=\int_{A} X_{t+1}\left(a_{t+1} \mid a^{t}\right) f\left(a_{t+1} \mid a^{t}\right) \mathrm{d} a_{t+1} . \quad a_{t} \in A$ denotes a particular realization of the stochastic productivity shock which is defined later. $a^{t}=\left(a_{0}, \ldots a_{t}\right)$ denotes the set of past realizations. The variables $c_{t}$ and $e_{t}$ denote consumption and effort while $\phi, \gamma, \psi$ are positive parameters. $d_{t}$ is a dummy variable which takes the value 1 when the workers is employed and zero otherwise. The household can either consume or save, through contingent claims. We assume that he has access to a complete system of markets on which he can trade contingent claims, which are purchased in period $t$ for period $t+1$ at price $\frac{p_{t+1}\left(a_{t+1} \mid a^{t}\right)}{p_{t}\left(a_{t} \mid a^{t-1}\right)}$. 
The value of the portfolio of the household is thus given by

$$
\int_{A} \frac{p_{t+1}\left(a_{t+1} \mid a^{t}\right)}{p_{t}\left(a_{t} \mid a^{t-1}\right)} b_{t+1}\left(a_{t+1} \mid a^{t}\right) \mathrm{d} a_{t+1} \text {. }
$$

This portfolio will give him an amount of $b_{t+1}\left(\hat{a} \mid a^{t}\right)$ of the good in period $t+1$ if $a_{t+1}=\hat{a}$ and zero otherwise. Hereafter and for convenience, we abstract from any explicit reference to $a_{t}$, but it should be clear for the reader that all variables are functions of $a_{t}$.

The household offers his work on the labor market at the real wage rate $w_{t}$, but has to pay $u_{t} w_{t}$ in terms of the unemployment insurance. ${ }^{4} u_{t}$ is the unemployment rate.

Our model differs from the standard RBC model is several points ${ }^{5}$. One of the most striking point is that labor does not enter in the utility function. This implies that the main mechanism at work in the model will not be the standard intertemporal labor substitution effect usually driving RBC models. In fact, in this class of models the household supplies inelastically one unit of time, and only a fraction of time will be employed by the firm. We call $l_{t}$ this fraction of time. Unemployment is thus expressed in terms of hours.

Effort enters the utility function only when the household works, namely when the dummy variable $d_{t}$ equals to one. One important point is that the utility drawn from the job itself (job satisfaction) is separable from the utility drawn from consumption so that effort is independent of wealth. We thus first solve for effort and then derive the optimal consumption-savings optimal plan of the household. Notice that the so-called effort function is the consequence of maximizing the utility with respect to $e_{t}$. In this model, the determination of effort relies on two effects. on one hand, households will rise their effort as soon as their current wage is higher than an alternative wage, $w_{t}^{a}$, which represents alternative opportunities on the labor market. On the other hand, effort increases when the current wage is higher than past wages. The parameters $\gamma$ and $\psi$ determines the sensitivity of effort to wage comparisons with the alternative wage and with past wages respectively.

Another important point of this model is that the real wage is not Walrasian, rather it is determined by the firm depending on the level of effort the household supplies. Thus, there will be periods in which households will be unemployed. This is captured by the dummy variable $d_{t}$. Since ex-ante all agents are assumed to be identical the unemployed will be drawn randomly, leading to an unemployment rate $u_{t}=1-l_{t}$.

If there is no insurance, unemployment introduces an ex post heterogeneity that will affect the optimal consumption - saving plan in the next period. Stated in another way, unemployed households have a lower income than employed ones, so that they will reduce their level of savings. The computation of the entire sequence of decisions for an individual implies that we have to know its entire story on the labor market. In order to avoid this kind of complexity, we assume, as in Danthine and Donaldson (1990), that unemployment insurance contracts are offered without transaction costs. Since households are risk averse, they will choose to be fully insured, so that they will preserve their wealth whether they are employed or not.

The set of first order conditions defining the optimal plan of the household can be stated as follows:

\footnotetext{
${ }^{4}$ The explicit treatment of the unemployment insurance is provided in an appendix.

${ }^{5}$ For additional discussion, see the surveys of Danthine and Donaldson (1993) and Langot (1993).
} 


$$
\begin{aligned}
& \frac{1}{c_{t}}=x_{t} \\
& e_{t}=\phi+\gamma \log \left(\frac{w_{t}}{w_{t}^{a}}\right)+\psi \log \left(\frac{w_{t}}{w_{t-1}}\right) \\
& \frac{p_{t+1}}{p_{t}}=\beta \frac{x_{t+1}}{x_{t}} f\left(a_{t+1} \mid a^{t}\right)
\end{aligned}
$$

where $x_{t}$ is the multiplier associated to the intertemporal budget constraint. Also the following transversality condition must hold

$$
\lim _{j \rightarrow \infty} \beta^{t+j} x_{t+j} b_{t+1+j}=0 .
$$

Equation (1) gives the Frischian demand for consumption. Equation (2) defines the effort function, that firms will take into account in their plans. The relation (3) corresponds to the traditional asset pricing formula given by Lucas (1978). It means that the price of contingent claims in state $a_{t+1}$ is determined by the discounted rate of intertemporal substitution, weighted by the occurrence probability of $a_{t+1}$. Finally, equation (4) furnishes a terminal condition to the evolution of $x_{t}$.

\subsection{The firm}

The firm produces an homogeneous good that can be consumed or accumulated. Its technology is described by the production function

$$
y_{t}=a_{t} k_{t}^{\alpha}\left(l_{t} e_{t}\right)^{1-\alpha}
$$

where $k_{t}$ denotes the firm's capital stock, $l_{t}$ the level of employment and $a_{t}$ a technological shock. $k_{t}$ is formed according to the traditional law of accumulation

$$
k_{t+1}=i_{t}+(1-\delta) k_{t}
$$

where $i_{t}$ denotes the level of investment chosen by the firm in period $t$ while $0<\delta<1$ is the constant depreciation rate.

The technological shock $a_{t}$ is assumed to be a stationary exogenous $A R(1)$ process

$$
\log \left(a_{t}\right)=\rho \log \left(a_{t-1}\right)+\varepsilon_{t}
$$

with $|\rho|<1$. $\varepsilon_{t}$ is a gaussian white noise with $E\left(\varepsilon_{t}\right)=0$ and $E\left(\varepsilon_{t}^{2}\right)=\sigma^{2}$.

In Becker's (1996) terminology, the inclusion of past wages in the wage norm can be achieved either as a personal norm, hence including the past wage perceived by the individual, or as a social norm incorporating the influence of past actions by peers and others. We then have to consider the two different cases in turn depending on the status of the past wages in the efficiency function. ${ }^{6}$

\footnotetext{
${ }^{6}$ Of course, one might consider a more general framework which is a combination of the two cases, in which part of the wage norm is social and part is personal.
} 


\subsubsection{The social norm case}

In this case the firm has no control over the "social capital" of its workers. This implies that past wages are treated as an externality. The wage setting behavior of the firm is then static. The firm seeks to maximize the sum of its discounted profit flows

$$
\max \sum_{t=0}^{\infty} \int_{A} p_{t}\left\{y_{t}-w_{t} l_{t}-i_{t}\right\} \mathrm{d} a_{t}
$$

subject to (5). Denoting by $q_{t}$ the Lagrangean multiplier associated with the law of motion of capital, the first order conditions are then given by

$$
\begin{aligned}
& q_{t}=1 \\
& (1-\alpha) \frac{y_{t}}{l_{t}}=w_{t} \\
& (1-\alpha) \frac{y_{t}}{e_{t}}\left(\frac{\gamma+\psi}{w_{t}}\right)=l_{t} \\
& q_{t}=\int_{A} \frac{p_{t+1}}{p_{t}}\left(\alpha \frac{y_{t+1}}{k_{t+1}}+(1-\delta) q_{t+1}\right) \mathrm{d} a_{t+1}
\end{aligned}
$$

as well as the transversality condition

$$
\lim _{j \rightarrow \infty} \int_{A} \frac{p_{t+1+j}}{p_{t+j}} q_{t+j} k_{t+1+j} \mathrm{~d} a_{t+1+j}=0
$$

Equation (7) together with (10) shows that the firm has a static demand for capital; the marginal value of capital in terms of profit shall be equal to its price on the financial market.

Equation (8) determines the optimal employment behavior of the firm. Since it maximizes its profit flow, it will hire workers until the marginal product of labor equals the real wage. This leads to the traditional employment behavior, but for the fact that the real wage is not settled as to clear markets. Equation (9) corresponds to the wage setting behavior of the firm. It states that the firm will increase wages until the marginal cost implied equals the marginal return in terms of effort. Combining (8) and (9) we find the well-known Solow's (1979) 's condition

$$
\frac{\partial e\left(w_{t}, w_{t}^{a}, w_{t-1}\right)}{\partial w_{t}} \frac{w_{t}}{e\left(w_{t}, w_{t}^{a}, w_{t-1}\right)}=1
$$

which implies in this model that the firm chooses the real wage in such a way that effort is constant over the business cycle because

$$
e_{t}=\gamma+\psi
$$




\subsubsection{The personal norm case}

The personal norm case differs from the preceding in that past wages are not treated as an externality. The firm now adopts a dynamic wage setting behavior: it recognizes that increasing wages today will affect the level of effort of its workers tomorrow. The program of the firm is then transformed. It maximizes the sum of its expected discounted profit flows subject to the law of motion of capital and the evolution of wages. Let $z_{t-1}=w_{t} / w_{t-1}$ denote the growth factor of the real wage. Denoting by $q_{t}$ the Lagrangean multiplier associated with the law of motion of capital and $s_{t}$ the Lagrangean multiplier attached to the low of motion of wages, the first order conditions are then given by equations (7), (8), (10) as well as

$$
\begin{aligned}
& (1-\alpha) \frac{y_{t}}{e_{t}} \frac{\psi}{z_{t-1}}+s_{t} w_{t-1}=0 \\
& s_{t}=(1-\alpha) \frac{y_{t}}{e_{t}} \frac{\gamma}{w_{t}}-l_{t}+\int_{A} \frac{p_{t+1}}{p_{t}} s_{t+1} z_{t} \mathrm{~d} a_{t+1}
\end{aligned}
$$

and the transversality conditions (11) and

$$
\lim _{j \rightarrow \infty} \int_{A} \frac{p_{t+1+j}}{p_{t+j}} s_{t+j} w_{t+j} \mathrm{~d} a_{t+1+j}=0 .
$$

The way in which investment decisions are taken is left unaffected by the change in the wage setting behavior. The employment choice still corresponds to the previous rule, but the level and the policy rule for the real wage is different.

Equation (12) together with (13) allows to understand the wage setting policy of the firm:

$$
\int_{A} \frac{p_{t+1}}{p_{t}}(1-\alpha) \psi \frac{y_{t+1}}{e_{t+1}} \mathrm{~d} a_{t+1}=(1-\alpha)(\psi+\gamma) \frac{y_{t}}{e_{t}}-w_{t} l_{t}
$$

First of all, it appears that the traditional Solow's condition does not hold anymore in this setting. Condition (15) can then be interpreted as follows: on one hand, increasing the real wage in period $t$ implies a rise in productivity - via the increase in the two components of the labor efficiency — net of a higher labor cost (right hand side). On the other hand, a higher wage in period $t$ leads to a lower efficiency in period $t+1$, inducing a loss in productivity (left hand side).

\subsection{The equilibrium}

We first have to specify the form of the alternative wage. We will consider that it is given by the arithmetic ${ }^{7}$ average of current wage and unemployment compensation, set to zero in this model:

$$
w_{t}^{a}=l_{t} w_{t}
$$

\footnotetext{
${ }^{7}$ This is a difference with Danthine and Donaldson (1990) since they use a geometric average with a non zero unemployment benefit. Our assumption, being simpler, implies that hours would not fluctuate at all if $\psi=0$.
} 
Equilibrium in financial markets implies that the demand for securities equals the value of the firm. Since returns to scale are constant, it can be shown that the value of the firm can be written as $V^{f}\left(k_{t}, w_{t}, a_{t}\right)=q_{t} k_{t}=k_{t}$ so that $b_{t}=k_{t}$ in equilibrium. Using this equilibrium condition and gathering together the equations which are common to the two models, we get a set of equation, denoted by $\mathcal{E}$ :

$$
\begin{aligned}
1 / c_{t} & =x_{t} \\
e_{t} & =\phi+\gamma \log \left(\frac{w_{t}}{w_{t}^{a}}\right)+\psi \log \left(\frac{w_{t}}{w_{t-1}}\right) \\
w_{t} & =(1-\alpha) \frac{y_{t}}{l_{t}} \\
x_{t} & =\beta \mathrm{E}_{t}\left[x_{t+1}\left(\alpha \frac{y_{t+1}}{k_{t+1}}+1-\delta\right)\right] \\
y_{t} & =a_{t} k_{t}^{\alpha}\left(e_{t} l_{t}\right)^{1-\alpha} \\
y_{t} & =c_{t}+i_{t} \\
k_{t+1} & =i_{t}+(1-\delta) k_{t} \\
w_{t}^{a} & =l_{t} w_{t}
\end{aligned}
$$

in which (21) is the good market clearing condition.

Definition 1 The decentralized equilibrium of the economy in the social norm case is a set of policy rules for $\left\{c_{t}, i_{t}, y_{t}, e_{t}, l_{t}, k_{t+1}, w_{t} ; t \geq 0\right\}$ such that $\mathcal{E}$ holds and

$$
e_{t}=\gamma+\psi
$$

Definition 2 The decentralized equilibrium of the economy in the personal norm case is a set of policy rules for $\left\{c_{t}, i_{t}, y_{t}, e_{t}, l_{t}, k_{t+1}, w_{t}, z_{t} ; t \geq 0\right\}$ such that $\mathcal{E}$ holds and

$$
\begin{aligned}
s_{t} w_{t-1} & =-(1-\alpha) \frac{y_{t}}{e_{t}} \frac{\psi}{z_{t-1}} \\
s_{t} & =\gamma \frac{l_{t}}{e_{t}}-l_{t}+\beta E_{t}\left[\frac{x_{t+1}}{x_{t}} s_{t+1} z_{t}\right] \\
w_{t} & =z_{t-1} w_{t-1}
\end{aligned}
$$

\section{The model and the labor market puzzle}

In order to evaluate the interest of our two models with respect to the labor market stylized facts, we adopt the standard RBC methodology. The preceding systems are loglinearized around the deterministic steady state. The system of linear difference equations is then solved using the method proposed by Farmer (1993). 
The different deep parameters are picked up in Danthine and Donaldson (1990). This implies $\alpha=0.36, \beta=0.99, \delta=0.025, \rho=0.95, \sigma=0.009, \gamma=0.9$. Considering the parameters of the effort function, the sensitivity to alternative wage, $\phi$, is always set so as to obtain an unemployment rate at steady state of $10 \%$. This implies approximatively $\phi=0.8$ in the personal norm case and $\phi=0.8+\psi$ in the social norm case.

Figure 1: Correlation between output and effort

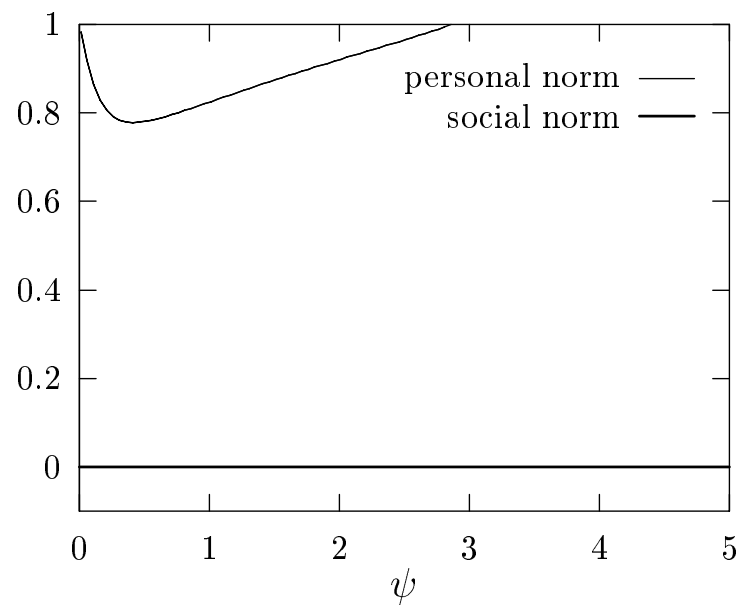

Since we do not have any useful information to determine a reasonable value for the sentivity of effort to past wages, $\psi$, we first compute various labor market moments for different values of $\psi$. The moments are computed using the frequency-domain technique advocated by Uhlig (1995). The theoretical moments are obtained after a pre-filtering by the Hodrick and Prescott's (1980) method with $\lambda=1600$. In the personal norm case, the parameter $\psi$ is allowed to vary between 0 and 2.86. Indeed, if $\psi$ is above 2.86 , the steady state looses its local stability in the saddle-point sense. ${ }^{8}$ In the social norm case, $\psi$ is allowed to vary between 0 and 5 . Notice that when $\psi=0$, the two models are effectively identical. They are also identical to the model of Danthine and Donaldson (1990) up to the definition of the alternative wage.

Figure 1 compares the correlation between effort and output for the two models. Considering first the social norm case, since the Solow's condition is verified, the real wage will adjust so that effort is constant over the business cycle. This implies that, in face of a positive productivity shock, wages have to increase in order to compensate the potential drop in effort linked to the reduction in unemployment. In the personal norm case, Figure 1 shows that effort is procyclical. In that case, in face of a positive productivity shock, it is optimal for firms to increase wages in order to increase effort. In fact, the rise in wages does more than compensating the effect of unemployment on effort. This contrasts sharply with the conclusion of Uhlig and Xu (1995) that effort movements predicted by efficiency wage theories are counter-cyclical. This is true only when the effort function is static.

Figure 2 presents the labor market moments for the personal norm case and for the social norm case. Notice first that the volatility exhibited by the personal case is higher

\footnotetext{
${ }^{8}$ When $\psi=2.86$ the steady state is non-hyperbolic and a flip bifurcation occurs.
} 
Figure 2: Labor market moments
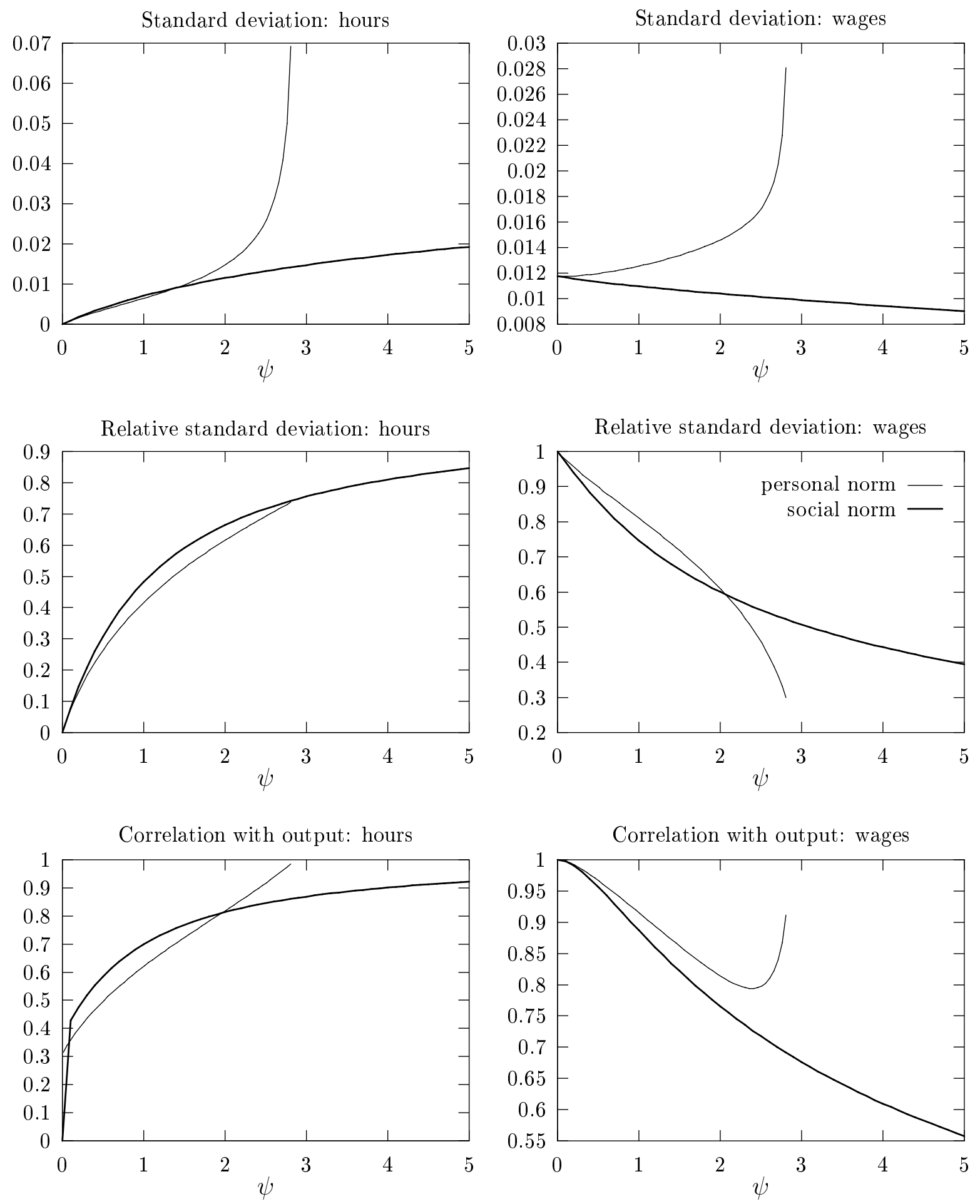
than the one generated by the social norm case. This can be understood in view of the previous discussion. In the personal norm case, effort is procyclical which requires larger movements in the real wage. Thus, the real wage - i.e. productivity - will display a higher volatility in the personal norm case. Since real wage will be more volatile in the personal case, so will be labor.

Notice that we have calibrated the standard deviation of the productivity shock using the usual value to facilitate the comparison with other RBC models. The above results suggest, however, that the personal norm model would be consistent with a lower standard deviation of the productivity shock. This contrasts again with the conclusion of Uhlig and $\mathrm{Xu}$ (1995) that efficiency wage models require unplausibly large movements in the technology parameters.

Further, Figure 2 shows that as $\psi$ increases the relative volatility of hours increases while the relative volatility of wages decreases. Moreover, the correlation between hours and output is an increasing function of $\psi$, whereas the correlation between wages and output decreases as $\psi$ rises.

This can be easily understood in the social norm case if we rewrite the efficiency function in equilibrium as

$$
\log \left(\frac{y_{t}}{l_{t}}\right)=a_{0}+\lambda \log \left(y_{t}\right)+(1-\lambda) \log \left(\frac{y_{t-1}}{l_{t-1}}\right) \text { with } \lambda=\frac{\gamma}{\gamma+\psi}
$$

As long as $\psi=0$, the volatility of productivity is given by that of output. But as soon as $\psi$ increases, the presence of past wages leads to a smoothing behavior of wage dynamics. This implies that the relative variability of productivity decreases with $\psi$. This can be interpreted as a dissociation between productivity and output as $\psi$ increases because the weight of past wages - i.e. productivity - increases with $\psi$. This dissociation can also explain the behavior of the correlation with output since the correlation between $y_{t} / l_{t}$ and $y_{t}$ shall be one when $\psi=0$, according to equation (28). As soon as $\psi \neq 0$, output and productivity are dissociated, so that this correlation is lowered.

The same reasoning can be applied to the labor demand, which can be rewritten, in the social norm case as

$$
\log \left(l_{t}\right)=b_{0}+\frac{\psi}{\gamma+\psi}\left[\log \left(y_{t}\right)-\log \left(y_{t-1}\right)+\log \left(l_{t-1}\right)\right] .
$$

This implies that when $\psi$ increases, the volatility of labor increases relative to that of output. The same happens as we consider the correlation between hours and output. This can be explained by the same dissociation phenomenon implied by the increase in $\psi$. As $\psi$ raises, the weight of past wages increases so that hours determination does not rely only on current wages, which are, in the standard RBC model, highly correlated to output, but also on past wages. As a consequence, the correlation between hours and output is lowered.

As it can be seen from Figure 2, this does not remain true in the personal case, because effort is procyclical in that case. This means that as soon as firms take into account past wages, they behave in such a way that variations in effort will break the dissociation.

In order to go beyond these qualitative considerations we choose a value for $\psi$ in the two cases. We have chosen to calibrate $\psi$ so as to reproduce exactly the correlation between 
hours and output. The evaluation of the models will thus be based on the three remaining moments of interest which are the relative standard deviations of hours and wages, and the correlation between wages and output. The values of $\psi$ which are compatible with an output-hours correlation of 0.86 are respectively 2.21 for the personal norm case and 2.8 for the social norm case.

Figure 3: Impulse response functions
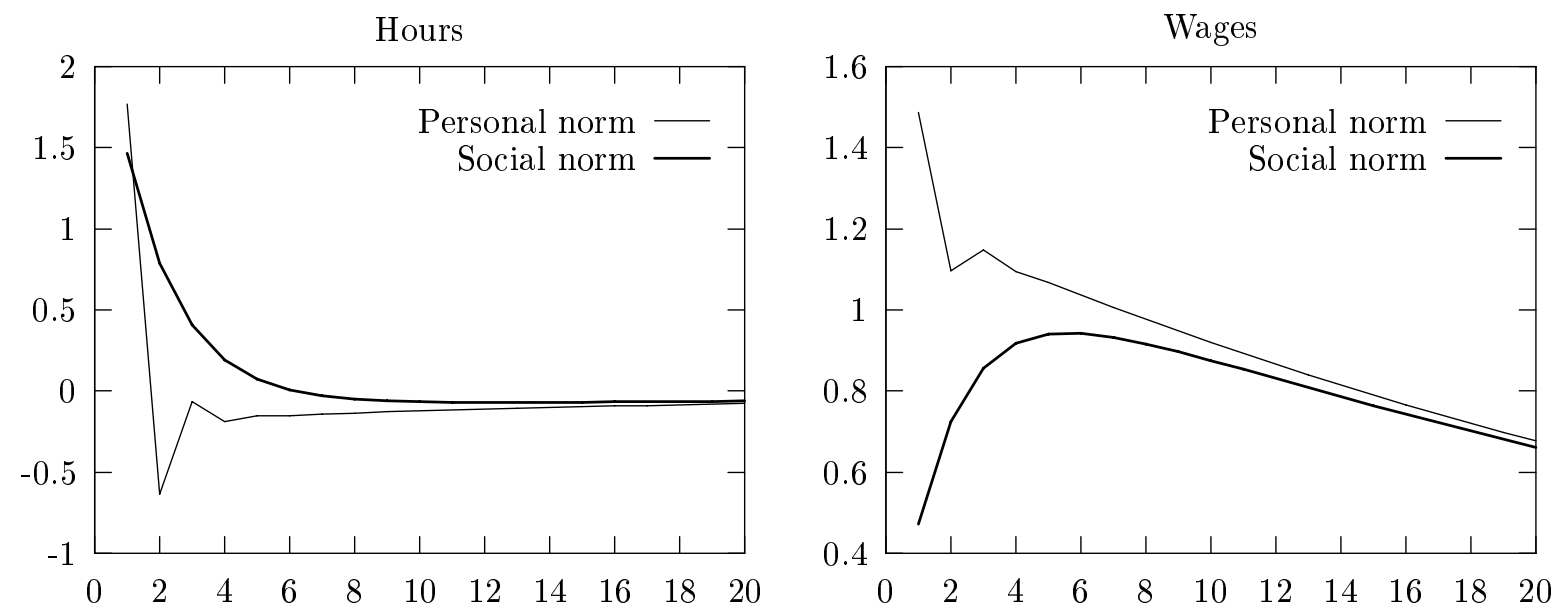

A first glance to the impulse response functions presented in Figure 3 indicates that, in the personal norm case, efficiency wage considerations induce a propagation mechanism that strongly magnifies the effect of productivity shocks on activity. Moreover, the personal capital model leads to oscillating impulse response functions. Since in the personal norm case optimal effort varies strongly procyclically, wages respond instantaneously in a stronger way than in the social norm case. In the social norm case, wages respond slowly to the productivity shock and their response reaches a peak after 6 quarters. This can be explained by the presence of a social norm; since it relies on past wages, it adjusts slowly to the new situation. Wages are to be risen continuously over 6 periods to keep effort constant. This slow movement in wages implies a large rise in hours during the first 3 quarters. These characteristics make the model useful to reproduce the stylized fact of large movements in hours and slow movements in wages.

We present in Table 1 the main stylized facts of the US economy as reported in Cooley and Prescott $(1995)^{9}$ together with the properties of various RBC models.

We take as benchmark Hansen's (1985) model with indivisible labor. The advange of this model compared to earlier work is to generate more volatility in hours. We next present the results of two models due to Danthine and Donaldson. The first one, an efficiency wage model of the gift exchange type, is very close to our model when $\psi=0$, except concerning the definition of the alternative wage. As it is stressed in the introduction, it performs poorly with respect to the labor market stylized facts, showing that efficiency wages are not synonymous to wage sluggishness. The second model of Danthine and Donaldson (1995) is one of the most performant non-Walrasian models so far it is based on labor contracts with two types of labor (young and old) and optimal minimum wage and unemployment benefits. In their survey, Danthine and Donaldson (1993) argue that

\footnotetext{
${ }^{9}$ The data on wages comes from the average real hourly earnings from the Establishment Survey.
} 
this model can be viewed as providing a resolution to the wage-employment variability puzzle. We argue however that our social norm model performs even better, in particular in that concerns the correlation between wages and output.

Table 1: Basic Statistics

\begin{tabular}{c|cccccccccccc}
\hline & U.S. dat. & \multicolumn{2}{c}{ Hansen } & \multicolumn{2}{c}{ Dan.-Don. } & Dan.-Don. & \multicolumn{2}{c}{ P. Norm } & \multicolumn{2}{c}{ S. Norm } \\
& & & $(1985)$ & $(1990)$ & $(1995)$ & $\psi=2.21$ & \multicolumn{2}{c}{$\psi=2.8$} \\
\hline & $(\mathrm{a})$ & $(\mathrm{b})$ & $(\mathrm{a})$ & $(\mathrm{b})$ & $(\mathrm{a})$ & $(\mathrm{b})$ & $(\mathrm{a})$ & $(\mathrm{b})$ & $(\mathrm{a})$ & $(\mathrm{b})$ & $(\mathrm{a})$ & $(\mathrm{b})$ \\
$c$ & 0.74 & 0.83 & 0.29 & 0.87 & 0.58 & 0.80 & 0.19 & 0.69 & 0.18 & 0.60 & 0.26 & 0.79 \\
$i$ & 4.79 & 0.91 & 3.24 & 0.99 & 6.46 & 0.86 & 3.45 & 0.99 & 3.61 & 0.99 & 3.33 & 0.99 \\
$l$ & 0.92 & 0.86 & 0.77 & 0.98 & 0.16 & 1.00 & 0.72 & 0.98 & 0.65 & 0.86 & 0.74 & 0.86 \\
$w$ & 0.44 & 0.68 & 0.28 & 0.87 & 0.83 & 1.00 & 0.35 & 0.91 & 0.55 & 0.80 & 0.52 & 0.69 \\
\hline
\end{tabular}

(a): Standard deviations relative to output.

(b): Contemporaneous correlations with output.

Let us now draw the main interests of our models compared to the previous studies. ${ }^{10}$ First, like all the models presented in table 1 our models mimic the ranking of relative volatilities of consumption, investment, hours and wages (except Danthine and Donaldson (1990)). All variables are procyclical.

Second, the social norm case displays a relative volatility of hours as high as Hansen's (1985) model without the need for the indivisibility assumption (implying an infinitely elastic labor supply). This is mainly due to the social norm assumption, as explained previously in the impulse response functions analysis. Moreover, the relative volatility of wages is well reproduced by both models. It is worth noting that if Hansen's model improves the reproduction of the relative volatility of hours, it is at the price of a deterioration in the reproduction of that of wages with respect to the basic canonical $\mathrm{RBC}$ model. Here, the social norm assumption allows for large movements in hours without lowering too much the variability of wages.

Third, when we consider the correlation between wages and output, the social norm model is able to reproduce almost exactly this correlation, which is in contrast with all other models. This is due to the dissociation that is introduced by the social norm between the evolution of wages and output dynamics. In the standard RBC model, as well as in all the other models we consider in table 1 (except the personal norm case), wages are determined by the marginal productivity of labor. Wages are therefore highly correlated with output. In the two models we consider, this is no longer true, since current wages also rely on past wages. But this effect is lower in the personal norm case, because firms try to counter this dissociation using their intertemporal behavior for effort.

Let us finally consider the implications of the models in terms of the instantaneous correlation between wages and employment. Previous research has shown that exisiting

\footnotetext{
${ }^{10}$ Notice that since $\psi$ is calibrated in order to match exactly the correlation between hours and output, consequently our comments will not rely on this moment.
} 
RBC models systematically overestimate this correlation; around 0.2 in actual data. The only way to lower this correlation was to add a second source of stochastic impulsions that affects labor supply. Indeed Christiano and Eichenbaum (1992) showed that introducing government expenditures shocks making labor supply more volatile could be a way to account for a lower correlation between wages and employment.

Table 2 shows that the social norm case allows to mimic closely the slightly positive historical correlation between wages and employment, without requiring the introduction of additional shocks. In this model, the effect of a technological shock on wages is initially lower than in the perfect competition case, lowering the positive link between wages and employment. Once again, the personal norm case does worse than the social norm one, but still does better than Hansen (1985) and Christiano and Eichenbaum (1992).

Table 2: $\operatorname{corr}\left(l_{t}, w_{t}\right)$

\begin{tabular}{ccccc}
\hline Historical $^{a}$ & Hansen $^{(1985)^{b}}$ & C.-E.(1992) & Pers. Norm & Social Norm \\
0.19 & 0.74 & 0.57 & 0.38 & 0.23 \\
\hline
\end{tabular}

${ }^{a}$ Taken from Fairise (1995)

${ }^{b}$ Taken from Hairault (1995)

\section{The dynamics of wages and employment}

Let us now turn our attention to the dynamics of wage and employment along the cycle. It is indeed interesting to evaluate the performances of our models in terms of crosscorrelogramms to see if the replacement of the intertemporal substitution mechanims (through labour supply) by efficiency wages considerations allows to mimic the dynamic pattern of aggregates on the labor market.

Figure 4 presents the cross-correlogramm between output and hours on one hand (left panel) and output and wages on the other hand (right panel). The theoretical moments from our models are compared with the empirical moments taken from Cooley and Prescott (1995). Concerning the cross-correlogramm between output and hours, our two models show a very bad performance. Although the models have been calibrated to match exactly the instantaneous correlation, it is clear that all other correlations are underestimated at all leads and lags. Concerning the cross- correlogramm between output and wages, it appears that the personal norm case underestimates the correlation between output and wages at all leads and lags. The social norm case underestimates leading correlations and overestimates lagging correlations although the overall pattern seems to be well reproduced. It is worth noting that the theoretical model predicts that wages are a leading indicator of the cycle which slightly contradicts the data.

Part of these disappointing results is due to the fact that there are less motives for intertemporal substitution in the labor supply. It is in fact not very surprising that our efficiency wages models do perform so badly in terms of cross-correlograms because the dynamics implied by our effort function is limited to a one-lag habit formation structure. 

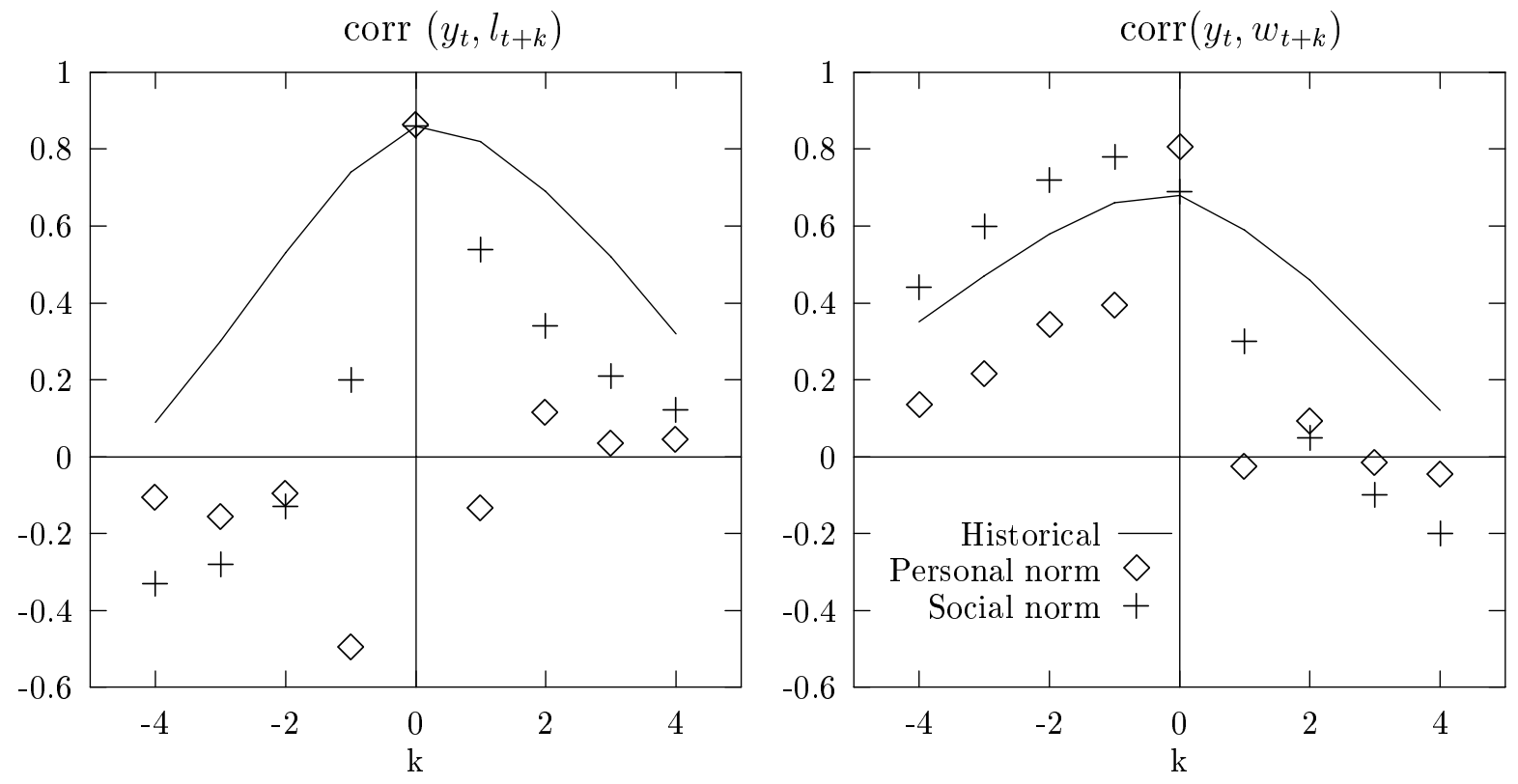

To solve this problem we assume more habit persistence in the formation of norms. Taking our inspiration in the litterature on consumers' habit formation, we define a habit stock as follows (see Ryder and Heal (1973)):

$$
w_{t}^{s}=\mu \sum_{i=1}^{\infty}(1-\mu)^{i-1} w_{t-i}^{s}
$$

$w_{t}^{s}$ is alternatively the stock of social capital or the stock of personal capital depending on the whole history of wages. $\mu$ is related to the mental depreciation rate of the household. When $\mu=1$ we retrieve our previous specification.

Preferences of the household are now described by

$$
\sum_{t=0}^{\infty} \beta^{t}\left[\log c_{t}-d_{t}\left(e_{t}-\phi-\gamma \log \left(\frac{w_{t}}{w_{t}^{a}}\right)-\psi \log \left(\frac{w_{t}}{w_{t}^{s}}\right)\right)^{2}\right] .
$$

The definition of equilibrium in the social norm case has now to take into account the modified effort function and the new accumulation rule of social capital. The definition of equilibrium in the personal norm case is modified more importantly; equations (25) and (26) should be replaced by

$$
\begin{aligned}
l_{t} & =\mu s_{t}+(1-\alpha) \frac{y_{t}}{e_{t}} \frac{\gamma+\psi}{w_{t}} \\
s_{t} & =\beta E_{t}\left[\frac{x_{t+1}}{x_{t}}\left((1-\mu) s_{t+1}-\psi \frac{1-\alpha}{w_{t+1}^{s}} \frac{y_{t+1}}{e_{t+1}}\right)\right]
\end{aligned}
$$

in which $s_{t}$ is now the Lagrangean multiplier associated with the accumulation rule of personal capital (30). 
This "enlarged" model has one additional parameter to calibrate, namely $\mu$. We therefore have to calibrate two parameters, $\psi$ and $\mu$, for which we do not have a priori information. We choose to exploit the information contained in the lead and lag structures of the correlogramms without imposing to match two particular moments. This corresponds to over-identifying the two parameters. ${ }^{11}$ Accordingly we minimize the distance between a series of moments and their empirical counterpart. The retained moments are the relative standard deviations of wages and employment to output and the correlations of wages and employment with output from lag 4 to lead 4 . The parameter $\phi$ is still used to obtain a steady state unemployment rate of $10 \%$. This implies 18 degrees of over-identification. This procedure gives the following result: Social case: $\phi=3.27, \psi=2.46, \mu=0.10$. Personal case: $\phi=1.35, \psi=6.46, \mu=0.11$. It is worth noting that the value of $\mu$ is nearly the same in the two cases, stemming for a relatively slow adjustment of norms to current wages.

Table 3: Basic Statistics: enlarged model

\begin{tabular}{c|cc|cccc}
\hline & \multicolumn{2}{|c}{ U.S. dat. } & \multicolumn{2}{c}{ P. Norm } & \multicolumn{2}{c}{ S. Norm } \\
\hline & $(\mathrm{a})$ & $(\mathrm{b})$ & $(\mathrm{a})$ & $(\mathrm{b})$ & $(\mathrm{a})$ & $(\mathrm{b})$ \\
$c$ & 0.74 & 0.83 & 0.28 & 0.88 & 0.32 & 0.91 \\
$i$ & 4.79 & 0.91 & 3.21 & 0.99 & 3.09 & 0.99 \\
$l$ & 0.92 & 0.86 & 0.79 & 0.99 & 0.74 & 0.99 \\
$w$ & 0.44 & 0.68 & 0.22 & 0.96 & 0.27 & 0.96 \\
\hline
\end{tabular}

(a): Standard deviations relative to output.

(b): Contemporaneous correlations with output.

Table 3 reports the basic properties of our two enlarged models and Figure 5 displays the two cross-correlograms. We first observe that the reproduction of relative volatilities is still accurate so that the introduction of a slow adjustment of norms does not deteriorate the ability of the model to generate volatile hours and sluggish wages. On the other hand, the improvement in the cross-correlograms is substantial. The time pattern of the correlations is adequately reproduced at all leads and lags. The price to pay for these improved cross-correlograms is a too high contemporaneous correlation with output of both wages and employment. Notice also that the difference between the social norm model and the personal norm model is substantially reduced so that we may no longer conclude that the social case clearly dominates. ${ }^{12}$

\footnotetext{
${ }^{11}$ This can be seen as a simulated method of moments in which we do not make any statistical inference.

${ }^{12}$ Moreover, the inspection of the impulse-response functions (not reported here) show that the propagation mechanism of the personal norm case still magnifies the effect of productivity shocks on activity but no longer implies oscillating impulse response functions.
} 
Figure 5: Cross-correlogramms: enlarged model
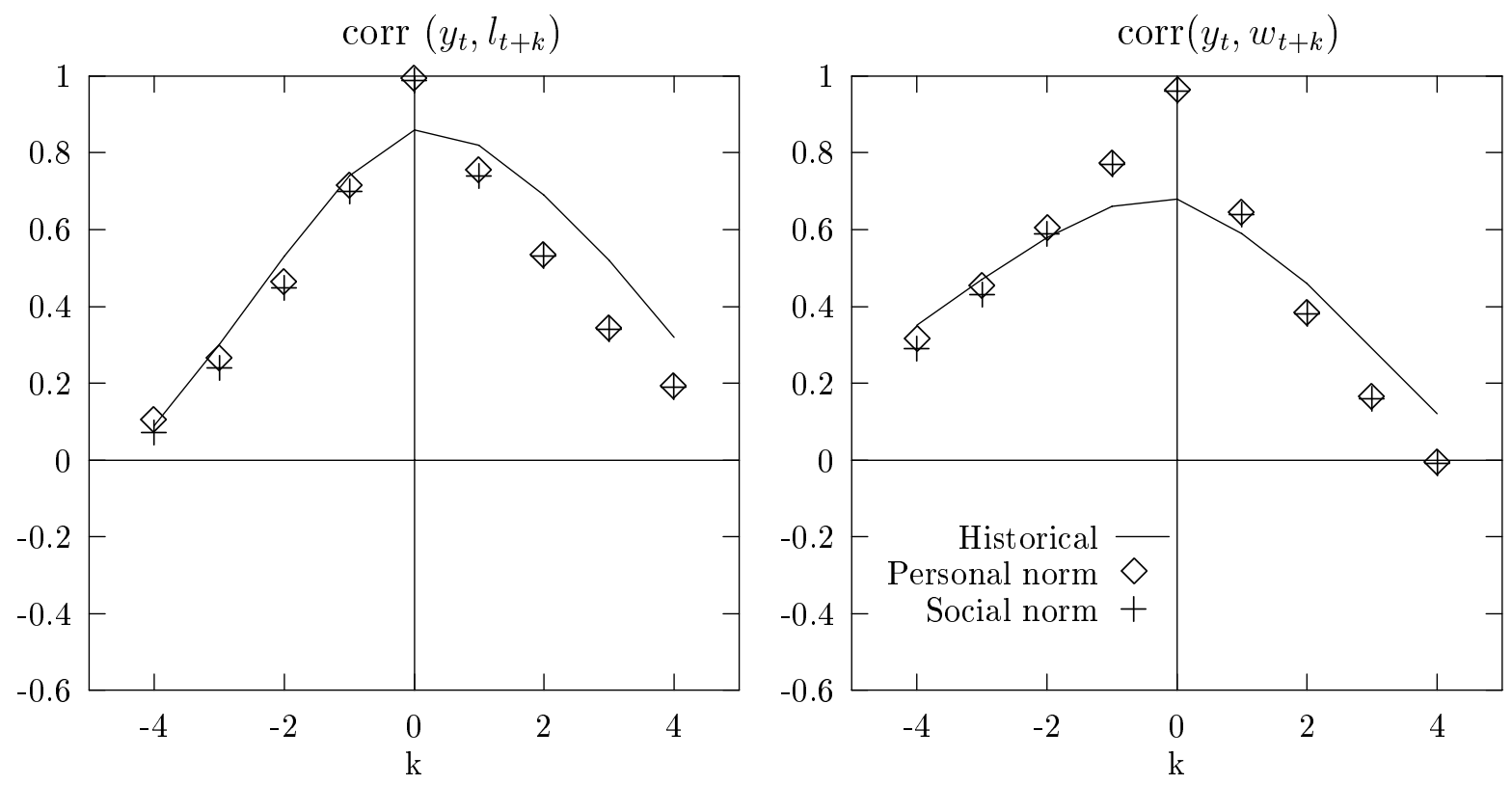

\section{Conclusion}

We have extended the benchmark RBC model amending its technology for efficiency wage considerations. In this model, effort depends on two effects. on one hand, households will rise their effort as soon as the current wage is higher than an alternative wage which represents alternative opportunities on the labor market. On the other hand, effort increases when the current wage is higher than past wages. The past wage is treated either as the worker's past wage (personal norm case) or as the past wage of society (social norm case).

In both models, the high variability of employment and the low variability of wages are reproduced without requiring additional features such as nominal rigidities, tastes shocks or indivisible labor. The social norm model is able to reproduce almost exactly the correlation between wages and output, which is in contrast with all other models. It also allows to mimic closely the slightly positive historical correlation between real wages and employment. In the personal norm case, efficiency wage considerations induce a propagation mechanism that magnifies the effect of productivity shocks on activity and implies oscillating impulse response functions.

A simple extension of the model allowing for a slow adjustment of norms to current situations improves substantially the reproduction of the cross correlations between wages, employment and output at different leads and lags.

Contrary to the pessimistic conclusion of Danthine and Donaldson (1990) and Uhlig and $\mathrm{Xu}$ (1995), our results show that efficiency wage considerations are useful to solve the business cycle puzzle when we allow for inter-temporal wage comparisons. 


\section{References}

Adams, J. and W. Rosenbaum (1962) "The relationship of worker productivity to cognitive dissonance about wage inequalities". Journal of Applied Psychology, 46:161-164.

Akerlof, G. (1982) "Labor contracts as partial gift exchange". Quarterly Journal of Economics, 97:543-569.

Becker, G. (1996) Accouting for tastes. Harvard University Press.

Blanchard, O. and S. Fischer (1989) Lectures on macroeconomics. MIT.

Christiano, L. and M. Eichenbaum (1992) "Current real business cycle theories and aggregate labor-market fluctuations". American Economic Review, 82:430-450.

Clark, A. (1996) "Are wages habit forming? evidence from micro-data". Working Paper, OCDE.

Cooley, T. and E. Prescott (1995) Economic growth and business cycles. In T. Cooley, editor, Frontiers of Business Cycle Research. Princeton University Press.

Danthine, J.-P. and J. Donaldson (1990) "Efficiency wages and the business cycle puzzle". European Economic Review, 34:1275-1301.

Danthine, J.-P. and J. Donaldson (1993) "Methodological and empirical issues in real business cycle theory". European Economic Review, 37:1-35.

Danthine, J.-P. and J. Donaldson (1995) Non-walrasian economies. In T. Cooley, editor, Frontiers of Business Cycle Research. Princeton University Press.

Fairise, X. (1995) Nominal wage contracts and the short-run dynamics of real wages. In P.-Y. Hénin, editor, Advances in Business Cycle Research. Springer Verlag.

Farmer, R. (1993) The macroeconomics of self-fulfilling prophecies. The MIT Press.

Fève, P. and F. Langot (1994) "The RBC model through statistical inference: an application with French data". Journal of Applied Econometrics, 9:S11-S35.

Goodman, P. (1974) "An examination of referents used in the evaluation of pay". Organizational Behavior and Human Performance, 12:170-195.

Hairault, J.-O. (1995) Presentation and evaluation of the real business cycle approach. In P.-Y. Hénin, editor, Advances in business cycle research. Springer Verlag.

Hansen, G. (1985) "Indivisible labor and the business cycle". Journal of Monetary Economics, 16:309-327.

Hodrick, R. and E. Prescott (1980) "Post-war U.S. business cycles: an empirical investigation". mimeo.

King, R., N. Plosser and S. Rebelo (1988) "Production, growth and business cycles: I". Journal of Monetary Economics, 21:196-232. 
Langot, F. (1993) La dynamique de l'emploi et du chômage dans les modèles d'équilibre général: fondements théoriques et évaluations empiriques. Thèse de Doctorat - Université de Paris I.

Lord, R. and J. Hohenfeld (1979) "Longitudinal field assessment of equity effects on the performance of major league baseball players". Journal of Applied Psychology, 64:19-26.

Lucas, R. (1978) "Asset prices in an exchange economy". Econometrica, 46:1429-1445.

Ryder, H. and G. Heal (1973) "Optimal growth with inter-temporally dependent preferences". Review of Economic Studies, 40:1-31.

Solow, R. (1979) "Another possible source of wage stickiness". Journal of Macroeconomics, 1:79-82.

Uhlig, H. (1995) "A toolkit for analyzing nonlinear dynamic stochastic models easily". Working Paper, FRB of Minneapolis.

Uhlig, H. and Y. Xu (1995) "Effort and the cycle: cyclical implications of efficiency wages". Working Paper, CentER (Tilburg).

Wadhwani, S. and M. Wall (1991) "A direct test of the efficiency wage model using UK micro-data". Oxford Economic Papers, 43:529-548.

\section{Appendix: The unemployment insurance system}

The problem of the representative household is to maximize her utility over its life-cycle:

$$
\max E_{0} \sum_{t=0}^{\infty} \beta^{t} \mathcal{U}_{t}
$$

where $\mathcal{U}_{t}=\pi_{t} U_{t}^{\ell}+\left(1-\pi_{t}\right) U_{t}^{u} \cdot \pi_{t}$ denotes the probability of being employed in period $t$, and is given, according to the law of large numbers, by $l_{t}$. $U_{t}^{n}$ is defined by:

$$
U_{t}^{n}= \begin{cases}\log \left(c_{t}^{\ell}\right)+G\left(e_{t}, w_{t}, w_{t-1}, w_{t}^{a}\right) & \text { if } n=\ell \\ \log \left(c_{t}^{u}\right) & \text { if } n=u\end{cases}
$$

where $G\left(e_{t}, w_{t}, w_{t-1}, w_{t}^{a}\right)=\left(e_{t}-\phi-\gamma \log \left(\frac{w_{t}}{w_{t}^{a}}\right)-\psi \log \left(\frac{w_{t}}{w_{t-1}}\right)\right)^{2}$

We assume that an insurance system allows households to buy an asset $g_{t}$ at a price $\tau_{t}$ which insures her against unemployment. Then the intertemporal budget constraint of given household is:

$$
\begin{array}{ll}
c_{t}^{\ell}+\tau_{t} g_{t}+\int_{A} \frac{p_{t+1}}{p_{t}} b_{t+1}^{\ell} \mathrm{d} a_{t+1} \leq b_{t}+w_{t} l_{t} & \text { if } n=\ell \\
c_{t}^{u}+\tau_{t} g_{t}+\int_{A} \frac{p_{t+1}}{p_{t}} b_{t+1}^{u} \mathrm{~d} a_{t+1} \leq b_{t}+g_{t} & \text { if } n=u
\end{array}
$$


Knowing that in period $t$ a household has a probability $l_{t}$ of being employed, the Bellman equation associated to that problem is given by:

$$
\mathcal{V}\left(\Delta_{t}\right)=l_{t} \mathcal{V}^{\ell}\left(\Delta_{t}^{\ell}\right)+\left(1-l_{t}\right) \mathcal{V}^{u}\left(\Delta_{t}^{u}\right)=\max \mathcal{L}_{t}
$$

in which $\Delta_{t}^{n}=\left\{b_{t}^{n}, w_{t-1}, a_{t}\right\}$ and $\mathcal{L}_{t}$ denotes the following Lagrangean:

$$
\begin{aligned}
\mathcal{L}_{t}= & l_{t}\left\{\log \left(c_{t}^{\ell}\right)+G\left(e_{t}, w_{t}, w_{t-1}, w_{t}^{a}\right)\right. \\
& \left.+\beta \int_{A}\left(l_{t+1} \mathcal{V}^{\ell}\left(\Delta_{t+1}^{\ell}\right)+\left(1-l_{t+1}\right) \mathcal{V}^{u}\left(\Delta_{t+1}^{u}\right)\right) f\left(a_{t+1} \mid a_{t}\right) \mathrm{d} a_{t+1}\right\} \\
& +\left(1-l_{t}\right)\left\{\log \left(c_{t}^{u}\right)+\beta \int_{A}\left(l_{t+1} \mathcal{V}^{\ell}\left(\Delta_{t+1}^{\ell}\right)+\left(1-l_{t+1}\right) \mathcal{V}^{u}\left(\Delta_{t+1}^{u}\right)\right) f\left(a_{t+1} \mid a_{t}\right) \mathrm{d} a_{t+1}\right\} \\
& +l_{t} x_{t}^{\ell}\left\{b_{t}+w_{t} l_{t}-c_{t}^{\ell}-\tau_{t} g_{t}-\int_{A} \frac{p_{t+1}}{p_{t}} b_{t+1}^{\ell} \mathrm{d} a_{t+1}\right\} \\
& +\left(1-l_{t}\right) x_{t}^{u}\left\{b_{t}+g_{t}-c_{t}^{u}-\tau_{t} g_{t}-\int_{A} \frac{p_{t+1}}{p_{t}} b_{t+1}^{u} \mathrm{~d} a_{t+1}\right\}
\end{aligned}
$$

The first order conditions associated to that problem are:

$$
\begin{aligned}
\frac{1}{c_{t}^{\ell}} & =x_{t}^{\ell} \\
\frac{1}{c_{t}^{u}} & =x_{t}^{u} \\
G_{e}\left(e_{t}, w_{t}, w_{t-1}, w_{t}^{a}\right) & =0 \\
\tau_{t} l_{t} x_{t}^{\ell} & =\left(1-\tau_{t}\right)\left(1-l_{t}\right) x_{t}^{u} \\
\frac{p_{t+1}}{p_{t}} l_{t} x_{t}^{\ell} & =\beta l_{t+1} x_{t+1}^{\ell} f\left(a_{t+1} \mid a^{t}\right) \\
\frac{p_{t+1}}{p_{t}}\left(1-l_{t}\right) x_{t}^{u} & =\beta\left(1-l_{t+1}\right) x_{t+1}^{u} f\left(a_{t+1} \mid a^{t}\right)
\end{aligned}
$$

The profit of the insurance company is given by

$$
\tau_{t} g_{t}-\left(1-l_{t}\right) g_{t}
$$

The maximization of the profit leads the company to charge $\tau_{t}=1-l_{t}$. Then from (36), we get

$$
x_{t}^{\ell}=x_{t}^{u}=x^{t}
$$

Thus, (33) and (34) imply that the level of consumption is the same for a employed and an unemployed household. Taking these results into account, we find that a given household always chooses to be fully insured $g_{t}=w_{t} l_{t}$. Given the specification of the effort function, this implies that the utility of a given household is the same whether she is employed or not. This implies that she is indifferent from working or not - i.e. supplying effort or not. 